\title{
Formas consensuais de composição de conflitos para a exploração de ferrovias
}

\author{
Marcos Juruena Villela Souto*
}

\section{A ferrovia como essential facility}

O desenvolvimento econômico, objetivo do Estado, tem, no escoamento da produção com vistas ao mercado, uma das suas mais relevantes ferramentas. Não resta dúvida, pois, que um corredor logístico, integrando modais, é fundamental para que a produção saia do ponto de origem e chegue ao mercado consumidor, interno e externo.

Também não restam dúvidas de que o conjunto de atividades econômicas movimentadas no entorno de um corredor logístico e de um complexo industrial é um elemento fantástico para a geração de empregos, rendas, consumo, circulação de riquezas e inclusão social.

Tudo isso mantém o mercado aquecido, num círculo virtuoso que viabiliza a liberdade de escolha e, por meio dela, a eficiência econômica.

Daí porque o processo de busca da eficiência tem na competição um dos seus fundamentos.

A liberdade dos usuários e consumidores escolherem os bens e serviços, bem como dos produtores e demais fornecedores chegarem ao mercado de consumo exige que sejam viabilizadas opções, para que a escolha se dê entre os melhores.

\footnotetext{
* Professor de direito administrativo regulatório do mestrado em direito da Universidade Candido Mendes (Ucam). Doutor em direito. Professor visitante da Universidade de Poitiers (França).
} 
As medidas constitucionais, legislativas e políticas de abertura da economia tiveram tal contexto em mira.

No entanto, nem sempre é possível falar em competição; há situações em que é inviável, tanto do ponto de vista físico como econômico, criar estruturas competitivas para permitir esse direito à liberdade de escolha no mercado.

É o que ocorre quando se fala em infraestrutura, tal como no caso das ferrovias. Nem sempre é viável a manutenção de toda a malha pelo monopolista ou, em sentido diverso, a criação de malha de infraestrutura alternativa. Além dos aspectos urbanísticos e ambientais, que podem impedir a ampliação, há situações em que o retorno de longo prazo e, portanto, de alto risco, não animam os investimentos.

Nesse passo, a estrutura existente, a ferrovia, poderia ser tratada como um monopólio natural. Caso submetida ao conceito clássico de direito de propriedade, o uso de tal estrutura ficaria sujeito ao interesse, disponibilidade e conveniência dos proprietários ou dos titulares do direito à sua exploração.

Isso, sem dúvida, afetaria os objetivos de eficiência econômica, positivados, no Brasil, nas mudanças constitucionais que ocorreram a partir de 1995, impactando, pois, a concretização do princípio da livre concorrência.

A competição pelo direito à exploração de malhas ferroviárias então exploradas pela Rede Ferroviária Federal S/A, em regime de monopólio, é um desses exemplos de substituição do Estado-executor pelo Estado-regulador, promotor da competição.

Daí porque, dando aplicabilidade ao princípio da função social da propriedade, se positivou, em sede infraconstitucional, o reconhecimento da essencialidade de tal estrutura monopolizada para o desenvolvimento econômico e social.

Em outras palavras, sempre que um monopólio natural, tal como o é a ferrovia, puder impactar significativamente o normal funcionamento do mercado, restringindo escolhas, desincentivando a eficiência e permitindo abusos de poder econômico, ${ }^{1}$ os instrumentos de defesa do mercado podem dar aplicabilidade aos princípios da livre concorrência e da função social da propriedade.

Na hipótese em exame, o instrumento clássico de defesa do mercado para prevenir ou minimizar os impactos negativos de um monopólio natural é a regulação. $^{2}$

A ferrovia é um exemplo clássico de monopólio natural definido como essential facility.

\footnotetext{
${ }^{1}$ Lei $\mathrm{n}^{\mathrm{o}}$ 10.233/2001: "Art. 12. Constituem diretrizes gerais do gerenciamento da infraestrutura e da operação dos transportes aquaviário e terrestre: [...] VII - reprimir fatos e ações que configurem ou possam configurar competição imperfeita ou infrações da ordem econômica".

${ }^{2}$ No dizer de Calixto Salomão (2001:38, 39 e 42), a existência de monopólios naturais é a justificativa central para a regulação.
} 


\section{O direito ao livre acesso à rede}

Em decorrência de tal enquadramento como essential facility, o titular do direito à sua exploração, por conta do "princípio da função social da propriedade" e do "princípio da livre concorrência", se submete ao "princípio do livre acesso". ${ }^{3}$

Em síntese, o titular do direito à exploração da ferrovia, essential facility que é, está impossibilitado de vedar o acesso aos usuários que preencham as condições para tanto.

Deve, pois, ser assegurado aos agentes econômicos, mediante pagamento e atendimento de condições técnicas, o livre acesso, vedada a discriminação que impeça o regular desenvolvimento das atividades dependentes de tal estrutura. ${ }^{4}$

Cabe, pois, à regulação, como função administrativa de defesa do mercado, orientar, estimular e zelar pela competição. ${ }^{5}$

Em síntese, o direito de livre acesso à rede representa o direito de ingressar, de fato, no mercado.

\section{O concessionário da ferrovia como sujeito passivo da obrigação de livre acesso}

O concessionário de uma ferrovia é o sujeito passivo tanto da obrigação de manutenção de tal estrutura como da obrigação de suportar o livre acesso, a quem se disponha a fazer o pagamento e preencher os requisitos técnicos.

Os agentes econômicos que atuam no setor do transporte ferroviário devem atuar em tráfego mútuo ou, sendo impossível (tal como uma essencial facility), conceder o direito de passagem aos demais operadores. ${ }^{6}$

\footnotetext{
${ }^{3}$ Tal consequência é assim explicada por Carlos Ari Sundfeld (2003:21-22): “Há uma teoria, da essential facility, criada no direito norte-americano, para fins concorrenciais, da qual resulta reconhecimento em favor das pessoas que desenvolvem atividades econômicas, de um direito subjetivo de usar as facilities, ou seja, as instalações alheias que sejam indispensáveis para o acesso ao mercado, para evitar que os donos das instalações impeçam o acesso de terceiro ao mercado e com isto inviabilize a prática de sua atividade. [...] É possível remanejar a rede em função das modificações dos traçados das ruas, o que não significa que seja um direito de uso gratuito. Há um direito subjetivo consolidado de acesso aos bens públicos para instalações das redes, mas pode ser também um direito remunerado (grifos nossos).

${ }^{4}$ Daí porque já se teve a oportunidade de afirmar que “os princípios do 'livre acesso' (aos dutos e redes) e da 'interconexão obrigatória' (às malhas e redes), por força dos quais as propriedades de redes vinculadas à prestação de serviços públicos ou de atividades econômicas relevantes, consideradas como 'monopólios naturais' devem suportar a sua utilização por terceiros interessados, mediante justa remuneração (cabendo ao regulador a solução dos conflitos)" (Souto, 2002:105).

${ }^{5}$ Nesse passo, Dinorá Adelaide Musetti Grotti (2000:62-63) explica que, como os setores de infraestrutura são, tradicionalmente, monopólios naturais, nos quais a competição seria inviável, cabe às normas regulatórias criar um espaço para introduzir a competição. Esta se faz por meio do livre acesso às redes, por força do qual os operadores devem facilitar aos demais o seu acesso, sem discriminações.

${ }^{6}$ Veja Decreto nํㅜ 1.832, de 4 de março de 2006, que aprova o Regulamento dos Transportes Ferroviários: "Art. 6. As Administrações Ferroviárias são obrigadas a operar em tráfego mútuo ou, no caso de sua
} 
Ocorre que o direito de terceiros ao livre acesso deve ser compatibilizado com o custo de manutenção, recuperação e ativação de uma rede; isto nem sempre é viável, dados os altos custos envolvidos.

Vale lembrar que o direito privado à exploração da ferrovia decorre de um contrato administrativo de concessão, para o qual o concessionário tem o direito ao equilíbrio econômico-financeiro.

De outro lado, a rede em regime de monopólio cria retornos crescentes de escala, isto é, quanto mais consumidores fazem parte da rede, mais útil ela é para o próximo consumidor. Logo, as redes já construídas passam a desempenhar um papel fundamental para o atendimento do usuário e para a adequada prestação de um serviço público. ${ }^{7}$

É evidente, pois, o conflito de interesses entre os usuários legitimados ao livre acesso às ferrovias e os titulares do direito à exploração de tal monopólio natural, de manutenção, ampliação e reativação nem sempre economicamente viável.

Em caso de não cumprimento adequado de suas obrigações, o concedente pode até mesmo retomar a atividade e os bens envolvidos, firmando novas delegações ou descentralizações, ou até mesmo assumindo a execução direta ${ }^{8}$ do serviço.

impossibilidade, permitir o direito de passagem a outros operadores. $\S 1^{\circ}$ As condições de operação serão estabelecidas entre as Administrações Ferroviárias intervenientes, observadas as disposições deste Regulamento".

${ }^{7}$ Esse dilema é assim exposto por Alexandre Santos de Aragão (2005:91): "Se a restrição ou mesmo a ausência de concorrência na gestão das infraestruturas é compreensível em razão do alto custo da sua gestão, aperfeiçoamento e ampliação, assim como da impossibilidade ou irracionalidade técnica, urbanística e econômica da sua duplicação, a mesma ratio não se aplica à prestação dos serviços públicos, salvo, naturalmente, naqueles sujeitos a obrigações de universalidade, em que a necessidade de prestações deficitárias pode justificar restrições à concorrência para que o serviço seja como um todo viabilizado. Todos esses fatores impõem ao gestor das redes (incumbentes) a obrigação de compartilhá-las com os prestadores dos serviços (entrantes), ainda mais quando também lhe foi outorgada a prestação de serviços, normalmente de natureza universal, o que muitas vezes foi necessário para preservar o equilíbrio econômico da empresa".

8 "Art. 80. Constitui objetivo do DNIT implementar, em sua esfera de atuação, a política formulada para a administração da infraestrutura do Sistema Federal de Viação, compreendendo sua operação, manutenção, restauração ou reposição, adequação de capacidade, e ampliação mediante construção de novas vias e terminais, segundo os princípios e diretrizes estabelecidos nesta Lei. Art. 81. A esfera de atuação do DNIT corresponde à infraestrutura do Sistema Federal de Viação, sob a jurisdição do Ministério dos Transportes, constituída de: [...] II - ferrovias e rodovias federais; III - instalações e vias de transbordo e de interface intermodal; IV - instalações portuárias. Art. 82. São atribuições do DNIT, em sua esfera de atuação: I - estabelecer padrões, normas e especificações técnicas para os programas de segurança operacional, sinalização, manutenção ou conservação, restauração ou reposição de vias, terminais e instalações; II - estabelecer padrões, normas e especificações técnicas para a elaboração de projetos e execução de obras viárias; III - fornecer ao Ministério dos Transportes informações e dados para subsidiar a formulação dos planos gerais de outorga e de delegação dos segmentos da infraestrutura viária; IV - administrar, diretamente ou por meio de convênios de delegação ou cooperação, os programas de operação, manutenção, conservação, restauração e reposição de rodovias, ferrovias, vias navegáveis, terminais e instalações portuárias; V - gerenciar, diretamente ou por meio de convênios de delegação ou cooperação, projetos e obras de construção e ampliação de rodovias, ferrovias, vias navegáveis, terminais e instalações portuárias, decorrentes de investimentos programados pelo Ministério dos Transportes e autorizados pelo Orçamento Geral da União; [veja Medida Provisória no 2.217-3, de 4 set. 2001] VIII - firmar convênios, 
O conflito não para por aí.

A instituição de uma nova malha ferroviária, seja de forma isolada ou em parceria com as entidades federadas interessadas na implantação de um corredor logístico, pode criar um ambiente concorrencial com as demais concessionárias federais, podendo produzir um risco de inviabilizar o retorno econômico idealizado para uma situação de monopólio.

Para equacionar essa diversidade de interesses, deve-se instaurar um mecanismo de solução de controvérsias.

\section{O papel da regulação na solução do conflito}

A existência de um monopólio natural legitima a regulação no desenvolvimento da atividade de exploração ferroviária e no uso do bem a ela vinculado.

A competência para a disciplina e prestação do serviço de transporte ferroviário é da União Federal (CF, art. 21, XII, $d)^{9}$ que após delegar, mediante licitação, a exploração das malhas antes exploradas pela RFFSA, instituiu pela Lei nº 10.233/2001 a Agência Nacional de Transportes Terrestres (ANTT), incumbida, não somente das funções de concedente, como da normatização e da solução de conflitos no setor.

A regulação dos conflitos concorrenciais tem como um de seus principais objetivos estruturar um mercado economicamente viável, preservando o livre acesso dos competidores, por meio da instalação de redes, de infraestruturas, notadamente em setores tratados como monopólio natural, como é o caso das ferrovias.

acordos, contratos e demais instrumentos legais, no exercício de suas atribuições; XII - administrar pessoal, patrimônio, material e serviços gerais; XIII - desenvolver estudos sobre transporte ferroviário ou multimodal envolvendo estradas de ferro; [incluído pela Lei no 11.314, de 2006] XIV - projetar, acompanhar e executar, direta ou indiretamente, obras relativas a transporte ferroviário ou multimodal, envolvendo estradas de ferro do Sistema Federal de Viação, excetuadas aquelas relacionadas com os arrendamentos já existentes; [incluído pela Lei $n^{\circ}$ 11.314, de 2006] XV - estabelecer padrões, normas e especificações técnicas para a elaboração de projetos e execução de obras viárias relativas às estradas de ferro do Sistema Federal de Viação; [incluído pela Lei $n^{\circ}$ 11.314, de 2006] VI - aprovar projetos de engenharia cuja execução modifique a estrutura do Sistema Federal de Viação, observado o disposto no inciso IX do caput deste artigo. [Incluído pela Lei $n^{-}$11.314, de 2006) §1º As atribuições a que se refere o caput não se aplicam aos elementos da infraestrutura concedidos ou arrendados pela ANTT e pela Antaq. [Redação dada pela Lei no 10.561, de 13 nov. 2002) Art. 84. No exercício das atribuições previstas nos incisos IV e V do art. 82, o DNIT poderá firmar convênios de delegação ou cooperação com órgãos e entidades da Administração Pública Federal, dos Estados, do Distrito Federal e dos Municípios, buscando

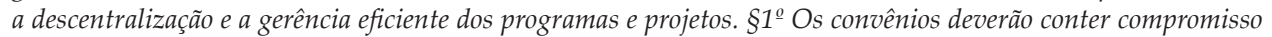
de cumprimento, por parte das entidades delegatárias, dos princípios e diretrizes estabelecidos nesta Lei, particularmente quanto aos preceitos do art. 83. $2^{2}$ O DNIT supervisionará os convênios de delegação, podendo declará-los extintos, ao verificar o descumprimento de seus objetivos e preceitos. [Veja Medida Provisória $n^{\circ}$ 2.217-3, de 4 set. 2001) Art. 89. Compete à Diretoria do DNIT: IV - autorizar a celebração de convênios, acordos, contratos e demais instrumentos legais; [...]."

9 "Art. 21. Compete à União: [...] XII - explorar, diretamente ou mediante autorização, concessão ou permissão: [...] d) os serviços de transporte ferroviário e aquaviário entre portos brasileiros e fronteiras nacionais, ou que transponham os limites de Estado ou Território; [...]." 
Tanto que o art. 20 da Lei no 10.233/2001 fixa que são objetivos da ANTT regular ou supervisionar as atividades de prestação de serviços e de exploração da infraestrutura de transportes, exercidas por terceiros, com vistas a "harmonizar", preservado o interesse público, os objetivos dos usuários, das empresas concessionárias, permissionárias, autorizadas e arrendatárias, e de entidades delegadas, "arbitrando conflitos de interesses" e impedindo situações que configurem "competição imperfeita" ou infração da ordem econômica.

Impõe-se a provocação de um processo administrativo regulatório. ${ }^{10}$

Logo, para a agência reguladora devem ser levados os interesses em tensão, para que, pela via processual, sejam harmonizados e devidamente fixados os direitos e as obrigações para cada um dos envolvidos. ${ }^{11}$

\section{Os direitos e deveres da concessionária da ferrovia a ser recuperada e mantida}

A pretensão de construção de uma malha adicional ou alternativa, em decorrência de eventual não atendimento adequado dos direitos de livre acesso, por conta de uma insuficiente manutenção da malha concedida, deve conviver com os direitos e deveres previstos em favor do concessionário.

Como dito, o dever de manter a infraestrutura cabe ao concessionário. ${ }^{12}$

Sobre tal dever, a Resolução ANTT nº 44/2002 estabelece procedimentos relativos às solicitações de suspensão e supressão de serviços de transporte ferro-

\footnotetext{
${ }^{10}$ Sobre as vantagens de instauração de um processo administrativo regulatório já se teve a oportunidade de afirmar que "o processo regulatório de conflitos, como dito, assume algumas peculiaridades em relação ao processo administrativo comum (conforme já visto ao examinar a função regulatória judicante), já que o conflito não envolve, necessariamente, a Administração e o particular, dando-se a oposição sobre interesses (econômicos, ecológicos, sociais) dentro de um quadro político (nível de vida, satisfação das necessidades e justiça e equidade social) ou sobre os meios para atendimento de um interesse comum, prestando-se o processo a auxiliar as partes e solucioná-la (Souto, 2002:349).

${ }^{11}$ Doutrinando especificamente para o setor ferroviário, Ricardo Wagner Carvalho de Oliveira (2005:220) caminha no mesmo sentido: "O bom êxito da atividade regulatória do setor ferroviário, assim como qualquer outro ramo de atividade regulada, subordina-se à processualização de toda a atividade administrativa da respectiva agência, visando, ao máximo, tornar impraticáveis condutas contaminadas pelo subjetivismo e pela arbitrariedade, incompatíveis, portanto, com a ideia de Estado de direito".

${ }^{12} \mathrm{O}$ art. 35 da Lei no 10.233/2001 fixa que o contrato de concessão terá como cláusulas essenciais as relativas ao modo, forma, condições e deveres relativos à exploração da infraestrutura e prestação dos serviços, o volume dos investimentos e os cronogramas de execução, as receitas complementares ou acessórias, os direitos, garantias e obrigações dos usuários, da Agência e do concessionário, os procedimentos para acompanhamento e fiscalização das atividades concedidas e para auditoria do contrato, os procedimentos relacionados com a transferência da titularidade do contrato e as regras sobre solução de controvérsias relacionadas com o contrato e sua execução, inclusive a conciliação e a arbitragem. Também deve o contrato tratar de sanções e casos de rescisão, caducidade, cassação, anulação e extinção do contrato, de intervenção ou encampação, incluindo os casos de declaração de inidoneidade.
} 
viário e de desativação de trechos, pelas concessionárias de serviço público de transporte ferroviário.

A norma reguladora invoca, como fundamento, o art. $6^{\circ}$ da Lei ํํ 8.987, de 13 de fevereiro de 1995, além dos arts. 3o e $4^{\circ}$ do Regulamento dos Transportes Ferroviários, aprovado pelo Decreto nº 1.832, de 4 de março de 1996.

Conforme seu art. $3^{\circ}$, a solicitação para supressão ou suspensão de serviços deverá ser objeto de requerimento à Agência Nacional de Transportes Terrestres (ANTT) e de comunicação da intenção aos usuários dos serviços no trecho alcançado pela medida, bem como às demais concessionárias que venham a ser afetadas, direta ou indiretamente, além do proprietário dos bens arrendados, quando for o caso.

Deve haver motivação comprovada da situação que justifica o pedido e indicação das "alternativas" existentes (art. $4^{\circ}$ ), podendo a ANTT demandar a reformulação das avaliações apresentadas (art. $6^{\circ}$ ).

A não observância de tais procedimentos pode dar ensejo a uma sanção pela ANTT, o que atinge, inclusive, os contratos firmados antes da criação da ANTT.

Isso porque a Lei no 10.233/2001 estabelece, em seu art. 50, que as empresas que, na data da instalação da ANTT ou da Antaq, forem detentoras de outorgas expedidas por entidades públicas federais do setor dos transportes, terão, por meio de novos instrumentos de outorga, seus direitos ratificados e adaptados. Os novos instrumentos de outorga serão aplicados aos mesmos objetos das outorgas anteriores e serão regidos, no que couber, pelas normas gerais.

É claro que um dos motivos pode ser a falta de rentabilidade do trecho que, eventualmente, pode levar à perda de equilíbrio do contrato de concessão.

Para a manutenção do equilíbrio, os contratos de concessão costumam fixar a remuneração por tarifa, que é o valor cobrado pelo transporte ferroviário de uma unidade de carga da "estação de origem" à "estação de destino", sendo certo que ainda são assegurados o reajuste e a revisão das tarifas. A revisão deverá acontecer caso ocorra alteração justificada de mercado e/ou de custos, de caráter permanente, que modifique o equilíbrio econômico-financeiro do contrato, podendo se dar por solicitação da concessionária, a qualquer tempo, ou por determinação da concedente, a cada cinco anos.

Esse direito é previsto para que sejam atendidas satisfatoriamente as obrigações das partes, entre as quais o dever de "prestar serviço adequado ao pleno atendimento dos usuários", sem qualquer tipo de discriminação e sem incorrer em abuso do poder econômico, atendendo às condições de "regularidade, continuidade, eficiência, segurança, atualidade, generalidade", cortesia na sua prestação e modicidade das tarifas; e, mais, o concessionário "deve cumprir e fazer cumprir as normas aplicáveis à ferrovia" e "zelar pela integridade dos bens vinculados à concessão, conforme normas técnicas específicas, mantendo-os em perfeitas con- 
dições de funcionamento e conservação, até a sua transferência à concedente ou à nova concessionária".

Isso reafirma o dever de a concessionária cumprir o Regulamento dos Transportes Ferroviários (RTF), aprovado pelo Decreto no 1.832, de 4 de março de 1996.

Especificamente quanto à manutenção dos bens, a concessionária assume o dever de cumprir todas as obrigações estabelecidas no contrato de arrendamento.

Claro que, de outro lado, a concessionária tem o direito de construir ramais, variantes, pátios, estações, oficinas e demais instalações, bem como proceder a "retificações de traçados" para a "melhoria" e/ou "expansão" dos serviços da malha. Depende, para tanto, da "prévia autorização da concedente".

A concessionária também tem, por contrato, o direito de "ampliar" a prestação do serviço concedido, inclusive mediante "participação em projetos públicos ou privados que visem promover o desenvolvimento socioeconômico da área onde se situa a malha", além de poder desenvolver sistema próprio de gerenciamento operacional que permita a integração do sistema ferroviário nacional (também a ser aprovado pela concedente); tudo isso, com cláusulas prevendo o direito de ter preservado o equilíbrio econômico-financeiro do contrato de concessão.

Portanto, as pretensões de expansão ou modificação dos trajetos existentes, ou a vulneração do monopólio atribuído pela constituição de vias alternativas deve considerar o conjunto de direitos já incorporados ao patrimônio jurídico da concessionária.

Ainda que seus deveres não estejam sendo cumpridos, a solução envolve um contencioso administrativo, no qual sejam assegurados os direitos à ampla defesa e ao contraditório.

Sendo o processo administrativo, conduzido perante a ANTT, a sede para a discussão do tema, é de duvidosa validade qualquer solução amigável envolvendo terceiros interessados sem que tal acordo seja legitimado pelo regulador.

\section{O interesse legítimo dos estados no desenvolvimento econômico regional}

Não resta dúvida, como dito, que a implantação de infraestrutura produz atividade econômica, circulação de riquezas, geração de empregos, inclusão social e, com isso, o atendimento dos objetivos contidos no art. $3^{\mathrm{o}}$ da Constituição da República que, em última instância, dão concretude ao princípio da dignidade da pessoa humana.

Portanto, é lógico que os estados envolvidos no corredor logístico vocacionado a escoar a produção, dos pontos de origem ao porto existente na região, têm o maior interesse em que as atividades e investimentos necessários para tanto não 
sejam inviabilizados pela inércia de terceiros, titulares ou não de direitos contratuais ou legais.

O desenvolvimento econômico é um bem maior e para isso se justificam, no caso concreto, tanto a concessão como a sua regulação.

Pode-se dizer que o poder público é um dos "agentes econômicos" legitimados a participar do processo regulatório. O Estado não é, meramente, um interventor, como se sua atuação decorresse, apenas, de algo excepcional, que foge à normalidade. ${ }^{13}$

Daí porque os estados estão entre os legitimados a participar de discussões e decisões da diretoria da ANTT para resolução de pendências que afetem os direitos de agentes econômicos ou de usuários de serviços de transporte, que devem ser precedidas de audiência pública (art. 68 da Lei no $10.233 / 2001$ ), ou mesmo para o exercício do direito que é conferido a qualquer pessoa, desde que seja parte interessada, para peticionar ou de recorrer contra atos das agências $\left(\S^{3}\right.$ ).

No entanto, o legítimo interesse - em função de sua missão de promover o desenvolvimento econômico regional - não se confunde, necessariamente, com competência para prestar o serviço.

A competência decorre da Constituição.

No caso da ferrovia, está-se diante de um serviço de transporte com uso de malha federal, previamente licitada pela União, para substituir um modelo em que o serviço era personificado numa empresa estatal federal. A malha integra, pois, o sistema viário federal, não podendo qualquer dos estados-membros, ainda que começando e terminando dentro do seu território, ${ }^{14}$ assumir a competência apenas por esse argumento. ${ }^{15}$

Claro que, também em decorrência da Constituição (art. 241), a partilha de competências pode admitir atos de cooperação entre as entidades federadas; isso, no entanto, como se verá adiante, exige um acordo de vontades. Por ora, frise-se, a competência é federal e só a União, que personifica o poder concedente na ANTT, pode decidir sobre a atribuição da malha, sua expansão ou modificação de traçado, ou, ainda, a admissão de vias alternativas ou complementares.

\footnotetext{
${ }^{13}$ Sobre o tema, afirma Fabio Nusdeo (1997:216): "[...] a figura mesma do Estado intervencionista se supera, pois a palavra intervenção traz em si o signo da transitoriedade, conota uma arremetida seguida de retirada, trai, em suma, uma situação excepcional, anormal. Não é essa, porém, a nova realidade. O Estado não mais intervém no sistema econômico. Integra-o. Torna-se um seu agente e um habitual partícipe de suas decisões. O intrometimento e posterior retirada poderão ocorrer neste ou naquele setor, nesta ou naquela atividade. Jamais no conjunto. Daí as diversas expressões para caracterizar o novo estado de coisas: economia social de mercado, economia dirigida; isonomia de comando parcial e tantas outras".

${ }^{14}$ Essas situações envolvem, usualmente, trens urbanos, de âmbito regional, que ligam subúrbios, distritos e municípios próximos à capital.

${ }^{15}$ Isso não se confunde com malhas regionais, de trens urbanos, que ligam municípios numa região dentro de um mesmo estado. Aí, não se tem malha federal.
} 


\section{Formas consensuais de composição dos conflitos}

Como visto, há direitos e deveres para a concedente, concessionária, usuários e interessados, dos quais decorrem divergências e dúvidas sobre os melhores métodos para a harmonização de todos eles.

Para tanto, a solução preconizada pelo ordenamento é o processo administrativo.

A agência reguladora é, em princípio, a instância legitimada por lei para tal harmonização de interesses, podendo, para fazer cessar os conflitos, por meio do arbitramento, impor uma decisão.

Todavia, não é apenas pela imperatividade que se soluciona conflitos.

A regulação é um dos instrumentos de atuação do Estado na economia e, como tal, envolvendo impacto no "princípio da livre-iniciativa", deve se submeter ao "princípio da proporcionalidade" e, ainda, ao "princípio da subsidiariedade".

Em outras palavras, o Estado regulador não deve impor medidas restritivas de liberdade se tal não for indispensável para a retomada da harmonia na vida em sociedade e no funcionamento do mercado.

Nesse passo, a busca de fórmulas não imperativas deve ser o ponto de partida. O conflito pode levar o regulador a resolvê-lo tanto por conciliação e mediação quanto por arbitragem. ${ }^{16}$

Não sem razão, a Lei nº $8.987 / 95$ prevê que o contrato de concessão deve tratar do modo amigável para solução de divergências.

Claro que tal norma, anterior à Lei no 10.233/2001, art. 50, deve ser interpretada como motivadora da busca do consenso perante a agência reguladora, especialmente porque a solução do conflito pode ensejar alteração dos termos do contrato, no que concerne aos direitos e às obrigações de concedente e concessionária.

A composição dos conflitos pelo consenso daria concretização aos princípios da economia processual e da segurança jurídica, viabilizando que todos os interessados e legitimados se componham, voluntariamente, não criando, pois, um cená-

\footnotetext{
${ }^{16}$ Alberto Bianchi (1998:54-55) afirma que: “Muy emparentada con la aplicación de la doctrina antimonopólica fue la doctrina de las instalaciones esenciales (essential facilities doctrines), formulada por la Corte Suprema en 1912. De acuerdo con esta doctrina, una empresa que controle una instalación o un medio esencial para que otras empresas puedan competir en un determinado mercado debe poner esa instalación o medio a disposición de sus competidores, en condiciones razonables y no discriminatorias. Tuvo aplicación en 'United States $v$. Terminal Railroad Association of St. Louis'. En este caso, varias compañias de ferrocarril controlaban conjuntamente el acceso al único puente sobre el río Mississipi en la ciudad de Saint Louis y se negaban a permitir el acceso al mismo a otras compañías que no integraban la asociación. La Corte consideró que el puente era una instalación o un medio de paso que resultaba esencial ('un cuello de botella', según la propia sentencia) para el tráfico ferroviario entre el este y el oeste de la nación; entendió que impedir el acceso a él suponía una restricción al libre comercio que violaba la Sherman Act y obligó a la asociación a permitir el acceso al puente a las compañías ferroviarias competidoras en condiciones razonables y siempre que fuera físicamente posible".
} 
rio de risco aos elevados investimentos exigidos para atendimento dos direitos em jogo e da própria promoção do desenvolvimento econômico, objetivo do Estado.

\section{O consenso regulatório}

Visto que o conflito pode ser solucionado por uma entidade regulatória independente, não necessariamente a decisão precisa vir por meio da imposição.

O ideal é que, antes da aplicação da imperatividade da decisão arbitral, consiga atingir a regulação do conflito por meio do consenso, sendo este o principal escopo da atividade judicante das agências. ${ }^{17}$

Como nem a Lei $n^{\circ}$ 10.233/2001, nem o Decreto $n^{\circ}$ 4.130/2002 delimitaram, exaustivamente, os procedimentos administrativos perante tal agência, aplica-se, de forma subsidiária, a Lei $n^{-}$9.784/99, que disciplina o processo administrativo em âmbito federal.

O consenso pode, inclusive, permitir a transferência da titularidade das outorgas, desde que o novo titular atenda aos requisitos para tanto (art. 30 da Lei n⿳o 10.233/2001; tal transferência só poderá ocorrer mediante prévia e expressa autorização da ANTT.

Isso não deixa de ser um formato de atendimento das próprias obrigações contratuais, de cumprir e fazer cumprir as disposições regulamentares do serviço e as cláusulas do contrato, de zelar pela boa qualidade do serviço, receber, apurar e solucionar as queixas e reclamações dos usuários, de estimular o aumento da qualidade, produtividade, preservação do meio ambiente e conservação, entre outras.

\section{A convenção de delegação de competência}

Outra via não litigiosa é a delegação de competência para os estados envolvidos na missão de cooperação para a implantação do corredor logístico ferroviário, sempre, é claro, considerando que há direitos atribuídos à concessionária.

Nesse passo, registre-se que, conforme art. 12, I, II e III, da Lei no 10.233/2001, uma das "diretrizes gerais" do gerenciamento da infraestrutura e da operação

\footnotetext{
${ }^{17}$ Diogo de Figueiredo Moreira Neto (2003:191) afirma que a busca do consenso representa o principal escopo da atividade judicante das agências: "Só se justifica a eventual impositividade de uma decisão administrativa a cargo do órgão regulador como ultima ratio, quando exauridas as instâncias de busca do consenso, e, ainda assim, desde que suportada pela devida motivação, que é um requisito essencial de qualquer atividade processualizada".
} 
dos transportes aquaviário e terrestre é a "descentralização" das ações, sempre que possível, promovendo sua "transferência" a outras entidades públicas, "mediante convênios de delegação", bem como promover a "integração física" e a "conjugação das operações" dos diferentes meios de transporte, para a movimentação intermodal mais econômica e segura de pessoas e bens, dando prioridade aos programas de ação e de investimentos relacionados com os "eixos estratégicos de integração nacional, de abastecimento do mercado interno e de exportação".

São decisões que cabem ser implementadas pelo poder concedente, ${ }^{18}$ que, conforme art. 24 da Lei no 10.233 , é a ANTT.

A ANTT, em sua esfera de atuação, tem como atribuições gerais editar atos de outorga e de extinção de direito de exploração de infraestrutura e de prestação de serviços de transporte terrestre, celebrando e gerindo os respectivos contratos e demais instrumentos administrativos.

De outro lado, a ANTT também tem a competência - e o dever - de reunir, sob sua administração, os instrumentos de outorga para exploração de infraestrutura e prestação de serviços de transporte terrestre "já celebrados antes da vigência da sua lei instituidora, resguardando os direitos das partes e o equilíbrio econômico-financeiro dos respectivos contratos".

No exercício de sua competência, já consta a "autorização legislativa" para "firmar convênios" de cooperação técnica e administrativa com órgãos e entidades da administração pública federal, dos estados, do Distrito Federal e dos municípios, tendo em vista a descentralização e a fiscalização eficiente das outorgas (art. 24, parágrafo único).

Logo, a competência para descentralizar a malha por convênios deve conviver com o dever de resguardar os contratos já firmados anteriormente à lei que instituiu a ANTT.

\footnotetext{
18 "Art. 22. Constituem a esfera de atuação da ANTT: [...] II - a exploração da infraestrutura ferroviária e o arrendamento dos ativos operacionais correspondentes; [...] Art. 25. Cabe à ANTT, como atribuições específicas pertinentes ao Transporte Ferroviário: I - publicar os editais, julgar as licitações e celebrar os contratos de concessão para prestação de serviços de transporte ferroviário, permitindo-se sua vinculação com contratos de arrendamento de ativos operacionais; II - administrar os contratos de concessão e arrendamento de ferrovias celebrados até a vigência desta Lei, em consonância com o inciso VI do art. 24; III - publicar editais, julgar as licitações e celebrar contratos de concessão para construção e exploração de novas ferrovias, com cláusulas de reversão à União dos ativos operacionais edificados e instalados; [...] Art. 28. A ANTT e a Antaq, em suas respectivas esferas de atuação, adotarão as normas e os procedimentos estabelecidos nesta Lei para as diferentes formas de outorga previstos nos arts. 13 e 14, visando a que: I - a exploração da infraestrutura e a prestação de serviços de transporte se exerçam de forma adequada, satisfazendo as condições de regularidade, eficiência, segurança, atualidade, generalidade, cortesia na prestação do serviço, e modicidade nas tarifas; II - os instrumentos de concessão ou permissão sejam precedidos de licitação pública e celebrados em cumprimento ao princípio da livre concorrência entre os capacitados para o exercício das outorgas, na forma prevista no inciso I, definindo claramente: [...]."
} 
Nos termos do art. 25 da Lei no 10.233/01, cabe à ANTT regular e coordenar a atuação dos concessionários, assegurando neutralidade com relação aos interesses dos usuários, orientando e disciplinando o tráfego mútuo e o direito de passagem de trens de passageiros e cargas.

A ela cabe arbitrar as questões não resolvidas pelas partes.

Cabe à ANTT, ainda, articular-se com órgãos e instituições dos estados, do Distrito Federal e dos municípios para conciliação do uso da via permanente sob sua jurisdição com as redes locais de metrôs e trens urbanos destinados ao deslocamento de passageiros; entenda-se, aqui, o ideário de integração logística, que, no caso em exame, representa a preocupação na implementação de um corredor logístico.

\section{O exercício da competência delegada por convênio}

Portanto, respeitados os direitos contratuais existentes, os estados interessados podem receber, por convênio, o direito à exploração das malhas ferroviárias federais, sejam as existentes, a serem mantidas, restauradas, ampliadas ou modificadas em seus trajetos, sejam as que a ela irão se integrar a partir de novos traçados.

Uma vez recebida a competência, o desempenho das atribuições a ela inerentes pode se dar como tradicionalmente se estrutura a administração pública para tanto.

A alternativa de gestão direta, por uma secretaria de Estado, é a menos recomendada. Cada vez mais, o poder central deve conservar funções de planejamento e controle, aplicando o "princípio da descentralização", previsto desde o DecretoLei no 200/67.

Também não se recomenda a gestão da competência recebida por meio de entidades na administração indireta. Os princípios da livre-iniciativa e da economicidade recomendam que sempre que se puder atender o interesse público com o uso de capitais privados, essa deve ser uma opção, de modo a liberar os escassos recursos públicos para situações que não admitem o emprego de capitais privados (quais sejam, as funções que exigem atos de império ou aquelas que não viabilizam lucratividade).

Mesmo a criação de uma sociedade de economia mista ou de uma empresa privada, com participação igualitária ou minoritária do poder público, sempre ensejaria a discussão sobre os critérios de escolha do parceiro privado. ${ }^{19}$

\footnotetext{
${ }^{19} \mathrm{O}$ modelo desenvolvido no estado do Rio de Janeiro, com a criação da parceria com a Peugeot-Citroën foi, na verdade, um programa de fomento, financiado com recursos do Fundo de Desenvolvimento Econômico e Social; o estado firmou diversos instrumentos destinados a viabilizar a implantação de uma fábrica de automóveis no município de Porto Real, tais como um acordo-programa, convênio fi-
} 
Vale notar que os mecanismos de fomento devem ser contemplados em lei e abertos a todos os interessados, conforme diretrizes que decorrem da aplicação do art. $174, \mathrm{CF} / 88$.

Ainda que o contrato de sociedade não seja contrato administrativo e não esteja contemplado nem no art. 37, XXI, CF, nem na Lei $n^{-0} 8.666 / 93$, há sempre o risco jurídico de se retardar o início das operações por discussões judiciais ou administrativas envolvendo a ausência de licitação no critério de escolha dos parceiros privados.

Chega-se, pois, à opção natural pela gestão desestatizada de serviços públicos, para a qual a regra do art. 175, CF, exige que a concessão - comum ou no modelo de PPP - seja "sempre" precedida de licitação.

Mais uma vez, ainda que o advérbio "sempre" comporte interpretações atenuantes - especialmente nas situações emergenciais ou nas de inviabilidade de competição - há o risco de retardamento do início das operações por conta de questionamentos administrativos e judiciais.

\section{Conclusão}

Tanto o Estado como o terceiro (privado) podem, em decorrência de um consenso em processo administrativo regulatório, conduzido perante a ANTT, com participação da concessionária, receber a competência para explorar, manter, expandir ou alterar o trajeto existente, ou criar malha complementar ou alternativa à existente.

No caso do terceiro, investidor privado, isso pode decorrer tanto de acordo para a cessão parcial do contrato por parte da concessionária ou ainda do consenso com a concessionária, aprovado pela ANTT, para a criação de malha complementar ou alternativa, ainda que concorrente.

Claro que, no caso de uma decretação da caducidade do contrato, a retomada da linha poderia ensejar o dever de promover uma licitação, salvo se atendidos os requisitos e condições previstos nos arts. 24, 25 e 26 da Lei no 8.666/93 para a contratação direta.

O consenso evitaria o risco jurídico de alegação de quebra do monopólio e inviabilização do contrato já existente pela criação de uma via concorrencial.

nanceiro, convênio de infraestrutura e compromisso de participação societária, mediante subscrição de novas ações, na Peugeot-Citroën do Brasil S.A. A presença do estado como acionista foi uma exigência feita pelo investidor privado para garantir a seriedade do programa; a ideia não era fazer do estado um explorador da atividade econômica, mas apenas instrumentalizar um mecanismo de fomento. Há registros de que o estado subscreveu, mas sequer teria integralizado o capital da Peugeot-Citroën do Brasil S.A. 
No caso do Estado, o recebimento de tal competência só pode decorrer de convênio. Assim, a autorização legislativa exigida pelo art. 241, CF, já estaria, para a ANTT, contida na Lei no 10.233/2001, devendo o Estado interessado obter sua autorização legislativa para receber a competência.

Para o Estado exercer a competência para exploração da ferrovia, que só pode receber mediante convênio - visto que a competência originária para a malha federal é da União, personificada na ANTT - ele deve, preferencialmente, promover uma licitação.

A escolha de parceiro privado, sem licitação, ainda que não seja repudiada pelo ordenamento jurídico, pode ensejar questionamentos quanto ao critério de escolha direta do parceiro privado, o que retarda o início de operações.

\section{Referências}

ARAGÃO, Alexandre Santos de. Servidão administrativa e compartilhamento de infra-estruturas: regulação e concorrência. Rio de Janeiro: Forense, 2005.

BIANCHI, Alberto B. La regulación económica. Buenos Aires: Editorial Ábaco de Rodolfo Depalma, 1998. t. I.

GROTTI, Dinorá Adelaide Musetti. Teoria dos serviços públicos e sua transformação. In: SUNDFELD, Carlos Ari (Coord.). Direito administrativo econômico. São Paulo: Malheiros, 2000.

MOREIRA NETO, Diogo de Figueiredo. Direito regulatório. Rio de Janeiro: Renovar, 2003.

NUSDEO, Fábio. Curso de economia: introdução ao direito econômico. São Paulo: RT, 1997.

OLIVEIRA, Ricardo Wagner. Direito dos transportes ferroviários. Rio de Janeiro: Lumen Juris, 2005.

SALOMÃO, Calixto. Regulação da atividade econômica: princípios e fundamentos jurídicos. São Paulo: Malheiros, 2001.

SOUTO, Marcos Juruena Villela. Direito administrativo regulatório. Rio de Janeiro: Lumen Juris, 2002.

SUNDFELD. Carlos Ari. Utilização remunerada do espaço público pelas concessionárias de serviço. Revista de Direito Municipal, jan./mar., 2003. 